\title{
Masculinidade em tempos de pandemia: onde o poder encolhe, a violência se instala ${ }^{1,2}$ Masculinity in pandemic times: where power decreases, violence increases
}

\author{
Dherik Fraga Santos ${ }^{a}$ \\ (iD) https://orcid.org/0000-0002-9351-7185 \\ E-mail: dherikळmsn.com \\ Rita de Cássia Duarte Lima ${ }^{a}$ \\ (i) https://orcid.org/0000-0002-5931-398X \\ E-mail: ritacdløgmail.com

\section{Stephania Mendes Demarchi ${ }^{a}$} \\ (D) https://orcid.org/0000-0002-2403-8842 \\ E-mail: stephaniamendes2008ळhotmail.com

\section{Jeanine Pacheco Moreira Barbosa ${ }^{a}$} \\ (i) https://orcid.org/0000-0003-1024-4378 \\ E-mail: jeaninepacheco®yahoo.com.br

\section{Marcos Vinicius da Silva Cordeiro ${ }^{a}$} \\ (D) https://orcid.org/0000-0002-8992-5514 \\ E-mail: marcosvscordeiroळgmail.com

\section{Marcelo Eliseu Sipioni ${ }^{a}$} \\ (D) https://orcid.org/0000-0003-1536-6374 \\ E-mail: mesipioniळyahoo.com.br

\section{Maria Angélica Carvalho Andrade} \\ (D) https://orcid.org/0000-0002-3690-6416 \\ E-mail: geliandradeळgmail.com \\ a Universidade Federal do Espírito Santo. Centro de Ciências \\ da Saúde. Programa de Pós-graduação em Saúde Coletiva. \\ Vitória, ES, Brasil.
}

\section{Correspondência}

Dherik Fraga Santos.

Av. Marechal Campos, 1468. Vitória, ES, Brasil. CEP 29047-105.

\section{Resumo}

No contexto de emergência da pandemia causada pela covid-19, o objetivo deste ensaio é refletir sobre as relações homem-poder-violência a partir das concepções de Hannah Arendt, problematizando o conceito normalizado de masculinidade hegemônica e buscando compreender o aumento de violência doméstica contra a mulher. Buscamos desconstruir a ideia de que existe um único modelo de masculinidade hegemônica que propõe uma dominação global dos homens sobre as mulheres, uma vez que mulheres também apresentam aspectos de masculinidade, sendo uma construção histórico-social que se transforma continuamente. Assim, diante das reformas históricas de gênero acrescidas da instabilidade provocada pela pandemia da covid-19, observa-se o aumento da violência domiciliar como efeito da diminuição do poder patriarcal, na tentativa de estabilizar o modelo de masculinidade definido por esse poder patriarcal, ou tenta-se reconstituí-lo (ressignificá-lo) em novas configurações.

Palavras-chave: Pandemias; Masculinidade; Violência Doméstica; Violência Contra a Mulher; Violência de Gênero.

\footnotetext{
1 O ensaio apresentado compõe parte da tese de doutorado do autor DF Santos, matriculado no Programa de Pós-graduação em Saúde Coletiva (PPGSC) da Universidade Federal do Espírito Santo (UFES), responsável pela pesquisa intitulada "O comportamento das práticas de dominação masculina sobre as mulheres sob o olhar de profissionais de saúde no período de isolamento social devido à Covid-19”, sob orientação da Prof. ${ }^{\text {a }}$ Dra Rita de Cassia Duarte Lima, também vinculada ao PPGSC da UFES.

2 A pesquisa é um ensaio, envolvendo apenas dados de domínio público que não identifica os participantes da pesquisa, sem envolvimento de seres humanos, portanto, de acordo com a Resolução no 466/12, não necessita de aprovação por parte do Sistema CEP-CONEP.
} 
The emergence of the covid-19 pandemic imposes the need for thinking about the narrowing of the man-power-violence relationship and the resignification of the place of men. In this context of social isolation, seeking to understand the increase in domestic violence against women, the objective of this essay is to reflect on the manpower-violence relations based on the concepts of Hannah Arendt, problematizing the normalized concept of hegemonic masculinity. Throughout this essay, we seek to deconstruct the idea that there is a single model of hegemonic masculinity and that it proposes a global domination of men over women, since women also present aspects of masculinity, which is a historical-social construction that is continuously transformed. Thus, in the face of historical gender reforms, and the instability caused by the pandemic of covid-19, there is an increase in domestic violence as an effect of the decrease in patriarchal power, in an attempt to stabilize the masculinity model defined by this patriarchal power, or the attempt to reconstitute it in new configurations.

Keywords: Pandemics; Masculinity; Domestic Violence; Violence Against Women; Gender-Based Violence.

\author{
"Os homens normais não \\ sabem que tudo é possivel." \\ Hannah Arendt
}

A Covid-19 apresenta considerável velocidade de propagação, em que o distanciamento social ampliado (DSA), o isolamento social e o bloqueio total (lockdown) se tornaram estratégias importantes para reduzir essa velocidade de transmissão, desacelerar os casos de óbito, oportunizar mais tempo para melhores planos terapêuticos e prevenir um colapso no sistema de saúde. Porém, essas mesmas medidas podem trazer importantes impactos econômicos e sociais, como o aumento do desemprego e das violências (Brasil, 2020).

Quando o vírus se alastra entre países, acirram-se as desigualdades de gênero, raça, classe, geopolíticas e econômicas, enquanto o caos e o medo revelam como a nossa sociedade se organiza e quais são os seus principais problemas.

A recomendação de isolamento social para impedir a propagação da covid-19 tem sido associada ao aumento da violência contra as mulheres, especialmente a violência doméstica, justificada pela preocupação com segurança, saúde e dinheiro (Mlambo-Ngcuka, 2020). Nesse momento desafiador, o aumento da precariedade da situação das mulheres e a consequente amplificação das suas vulnerabilidades revela a necessidade de responder às consequências imediatas e de longo prazo da atual crise (Acabar, 2020).

Diante disso, não se pode contestar ou ignorar as estatísticas referentes ao envolvimento dos homens com a violência doméstica, porém, é necessário ultrapassar as explicações fragmentadas sobre o fenômeno centradas nos modelos hegemônicos de masculinidade socialmente legitimados, que naturalizam a violência como um atributo dos homens, capaz de gerar relações humanas violentamente conflituosas nessa conjuntura de isolamento social. É importante destacar que a masculinidade hegemônica se encontra associada principalmente às características negativas, que retratam os homens como não emocionais, independentes, não cuidadores, agressivos e não 
passionais. Essas características são vistas como causas de práticas tóxicas, incluindo a violência física e de comportamento criminoso (Connell; Messerschmidt, 2013).

Embora a masculinidade hegemônica seja normativa, é importante destacar que ela não se assumiu frequente num sentido estatístico, uma vez que apenas uma minoria dos homens talvez a adote. Entretanto, a partir do modelo estabelecido, a masculinidade hegemônica "incorpora a forma mais honrada de ser um homem, ela exige que todos os outros homens se posicionem em relação a ela e legitima ideologicamente a subordinação global das mulheres aos homens" (Connell; Messerschmidt, 2013, p. 245).

Afirma-se a masculinidade como uma configuração de práticas em torno da posição dos homens na complexa estrutura das relações de gênero, todavia, falar dessa configuração de práticas significa colocar a ação em destaque, assumir que ações têm uma racionalidade e um significado histórico. Contudo, isso não quer dizer que a prática seja necessariamente racional, como a prática da violência (Connell; Messerschmidt, 2013).

Um tema central a ser discutido dentro do debate da violência é o questionamento da existência de um masculino universal. Acredita-se que, da mesma forma que não se pode falar sobre "uma mulher", não é possível conceber como natural e única a identidade masculina. Pelo contrário, é necessário desnaturalizar esse conceito enquanto uníssono e reconhecer que a masculinidade não é essência, mas historicamente construída, devendo, portanto, ser relativizada com relação às intersecções, tais como etnia, classe social, orientação sexual, religiosidades, dentre outros, que apontam para a diversidade de comportamentos e experiências masculinas ao longo da história (Connell; Messerschmidt, 2013). Nesse sentido, "o conceito de masculinidades, com ênfase na pluralidade do termo, impulsionou o questionamento à noção de masculinidade hegemônica, a qual incidia sobre a noção de homem, enquanto categoria naturalista e essencialista" (Batista; Lima, 2017, p. 176).

Outro aspecto central a ser destacado é a definição de violência como dominação própria das relações humanas, marcadas pela ausência do diálogo e pela instrumentalização do sujeito (Arendt, 2008).
A violência se instala onde o poder se encolhe (Arendt, 2009) e, nesses tempos de pandemia, esse conceito é fundamental para buscar compreender a instrumentalização do sujeito, a fragilidade e a aniquilação da fonte do poder legítimo - as interações humanas mais igualitárias - e a consequente perda da condição humana, relacionadas à crescente violência doméstica. É importante ressaltar que poder, em Hannah Arendt, relaciona-se à dimensão de legitimidade, autoridade, significação, potência e constituição política, devendo ser compreendido como a capacidade humana, não apenas para agir, mas também para agir em concerto, ou seja, o poder é concebido como convivência, ação em conjunto (Arendt, 2009).

A emergência da pandemia reclama enfaticamente pensar o estreitamento da relação homem-poderviolência e a ressignificação do lugar dos homens na sustentação da vida reprodutiva, dos laços emocionais e do cuidado. Nesse contexto de isolamento social, buscando compreender o aumento de violência doméstica contra a mulher, o objetivo deste ensaio é refletir sobre as relações homempoder-violência a partir das concepções de Hannah Arendt, problematizando o conceito normalizado de masculinidade hegemônica.

\section{Masculinidade hegemônica: reflexões sobre a normalização do conceito}

A prática de domínio dos homens sobre as mulheres não se dá apenas por meio da violência, apesar da possibilidade de ser sustentada por esse recurso. Essa hegemonia masculina significa ascendência atingida por meio da cultura, das instituições e da persuasão (Connell; Messerschmidt, 2013). Contudo, a depender desse contexto cultural e histórico, frequentemente ser violento pode ser caracterizado como um traço da masculinidade hegemônica local (Connell; Messerschmidt, 2013). Dessa forma, a violência contra a mulher vem sendo compreendida como um padrão ligado à masculinidade hegemônica, seja como um efeito mecânico, no qual as agressões são as consequências dessa masculinidade tóxica, seja por meio da busca da manutenção dessa dominação. Com esse entendimento, a violência contra a mulher apareceria como um exercício 
disciplinar ou como sinal de virilidade em sua máxima potência. No entanto, o conceito de masculinidade hegemônica não pode ser pautado por uma prática contínua de dominação coletiva dos homens sobre as mulheres, pois a violência e outras práticas tóxicas não são características essencialistas de todas as masculinidades hegemônicas, uma vez que elas são plurais e se manifestam de formas diferentes nos níveis local, regional e global (Connell; Messerschmidt, 2013).

A masculinidade é definida como uma configuração de práticas projetadas sobre as estruturas das relações de gênero. A sociedade (re) produz, historicamente relações de gênero (Connell; Messerschmidt, 2013) que em determinadas situações permitem a manutenção da dominação coletiva dos homens sobre as mulheres, sendo definida como masculinidade hegemônica. Não é incomum que, em algumas ocasiões, a masculinidade hegemônica seja identificada como masculinidade tóxica.

A dominação dos homens e a subordinação das mulheres representam um processo histórico, não um sistema auto reprodutor. A "dominação masculina” é aberta à contestação e demanda um esforço considerável à sua manutenção. Há uma série de estudos que mostram as táticas de manutenção da dominação através da exclusão das mulheres (Connell; Messerschmidt, 2013).

Com isso, é importante ressaltar que a masculinidade hegemônica se expressa de diferentes maneiras. Na hegemonia interna, ocorre a ascendência social de homens sobre outros homens, enquanto externa ocorre a dominação dos homens sobre as mulheres. Tais diferenças precisam ser observadas com cautela, pois devem ser consideradas as múltiplas masculinidades e feminilidades, além dos papéis dinâmicos de suas relações. Somada a essas formas de dominação, Connell e Messerschimidt (2013) afirmam que a masculinidade hegemônica é analisada em três níveis geográficos: local (construídas nas arenas da interação face a face das famílias, organizações e comunidades imediatas), regional (construídas no âmbito da cultura ou do Estado-nação) e global (construídas nas arenas transnacionais das políticas mundiais, da mídia e dos comércios transnacionais).
Nesse sentido, a crise da pandemia deve ser compreendida como uma oportunidade de desvelar a essência dos problemas relacionados à violência, que ficaram encobertos na máscara dos preconceitos, como a ideia de que toda masculinidade é tóxica. Dessa forma, compreende-se que a crise aumenta quando se responde a ela com preconceitos (juízos pré-formados) que acabam por impedir que a realidade seja vista como uma oportunidade de reflexão (Arendt, 2016).

Diante do exposto, o conceito de masculinidade hegemônica não pode ser compreendido como uma característica inerente aos homens, sendo necessário abandonar esse caráter essencialista, uma vez que mulheres também apresentam aspectos das masculinidades hegemônicas. Nesse sentido, a masculinidade não é uma entidade fixa encarnada num corpo ou nos traços de personalidade dos indivíduos masculinos, mas são configurações de práticas que são realizadas na ação social e, dessa forma, as masculinidades podem ser postas em ato por pessoas com corpos femininos (Connell; Messerschmidt, 2013).

Sendo assim, não se pode fazer uma análise simplista, que beira o preconceito, a partir do pressuposto de que há uma dominação global dos homens sobre as mulheres, já que convivemos com múltiplas masculinidades e diferentes formas de se relacionar com elas. Seguindo essa ideia, não existe uma masculinidade única, universal, o que existe são processos de produção de masculinidades sujeitadas construídas a partir de modelos estabelecidos (Connell; Messerschmidt, 2013), inscritos em um contexto relacional (Batista; Lima, 2017).

O conceito de masculinidade hegemônica, neste ensaio, é compreendido como uma pluralidade de masculinidades, hierarquizadas, que coexistem numa relação de subordinação por parte de masculinidades não hegemônicas (Figura 1). Esses padrões múltiplos de masculinidade se apresentam em diversos contextos, institucionais e culturais, evidenciando que algumas masculinidades são socialmente mais centrais, sendo referências para outras, tornando-se hegemônicas. Destaca-se que essa hegemonia não é obtida pela força, mas pelo consenso cultural, pelos discursos dominantes e institucionalizados, acarretando a marginalização e a deslegitimização das outras masculinidades. 


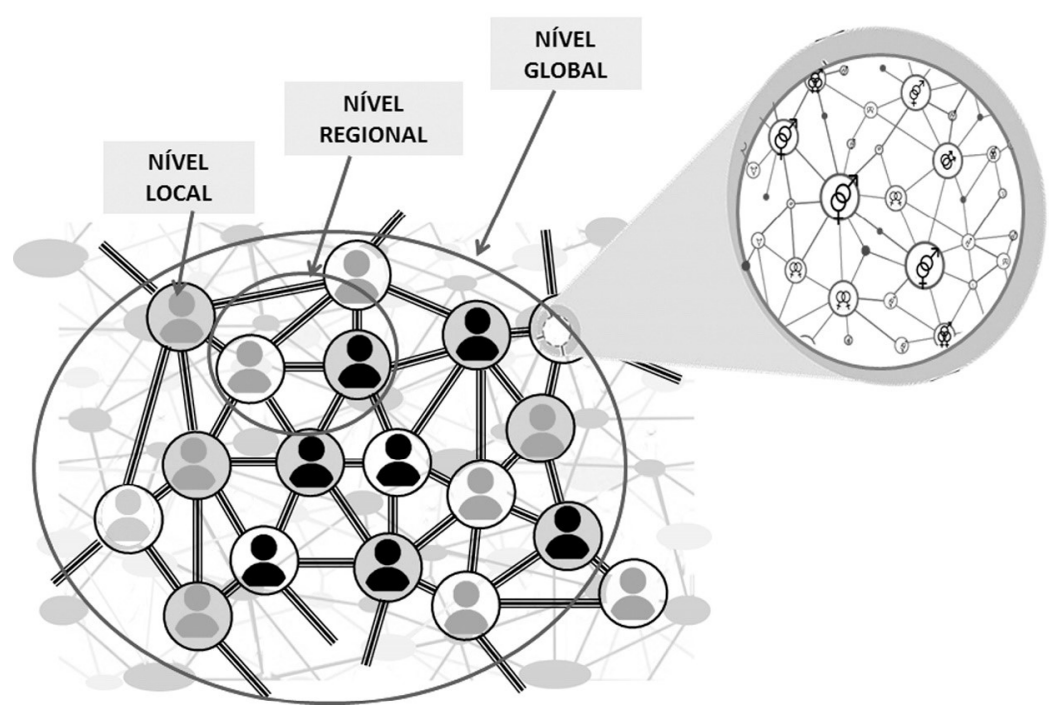

Esse processo de hegemonia, que tem numerosas configurações, se dará por meio da (re)construção de exemplos que têm autoridade e potência para produzir a imagem ideal de masculinidade padrão e normativa, não necessitando estar presente na vida diária da maioria de meninos e homens (Connell; Messerschmidt, 2013).

É importante ressaltar que o conceito de masculinidade hegemônica é uma construção histórico-social, em constante transformação, gerando mudanças nas relações de gênero, suscitando novas estratégias nas relações de poder e resultando na redefinição das masculinidades socialmente aceitas.

A partir do modelo de masculinidade hegemônica instituído e aceito, são construídas expectativas sociais sobre o perfil dos homens, esperando que sejam provedores de suas famílias, sexualmente dominantes, apresentem comportamentos que envolvam riscos, tenham dificuldades para demonstrar ou discutir suas emoções ou procurar ajuda. Esse perfil está associado às maiores taxas de vícios, suicídio, homicídio e acidentes de trânsito entre os homens, promovendo também o surgimento de doenças crônicas não transmissíveis como hipertensão, problemas cardíacos, diabetes, dentre outras (PAHO, 2019).

Além de atingir a saúde dos homens, esse padrão de comportamento leva a desfechos negativos também para crianças e mulheres, relacionando-se à violência interpessoal, às infecções sexualmente transmissíveis, à paternidade ausente e à gravidez imposta (PAHO, 2019).

Nesse cenário, os riscos das masculinidades dominantes podem ser acentuados ao agregar vulnerabilidades, às quais os homens são expostos, tais como: ser pobre, imigrante, jovem, indígena, ou afrodescendente, omissão de morbidades, mortalidade elevada, não ser heterossexual e estar desempregado. Tais vulnerabilidades contribuem para que a socialização das masculinidades dominantes esteja exposta a uma tríade de comportamentos de risco à saúde, composta através da socialização do homem em relação às mulheres e crianças, em relação a outros homens e em relação ao próprio homem (PAHO, 2019).

Mesmo a violência, pertencente ao grupo de causas externas, possuindo um impacto expressivo na morbimortalidade do homem, é ainda um aspecto pouco explorado no debate em torno da Política Nacional de Atenção Integral à Saúde do Homem (PNAISH), instituída em 2009. Desse modo, questionar a saúde do homem e a questão social da violência é uma discussão necessária, ao contextualizar as tensões existentes na constituição dessa política de saúde.

Os homens têm sido o grande ator ausente na formulação da PNAISH, de forma que nunca foi fruto de reivindicações. Seguem distantes dos 
espaços de cuidados e das ações de saúde, sobretudo, aquelas oferecidas no âmbito da Atenção Primária. Tal postura diverge da construção da Política de Atenção Integral à Saúde da Mulher (PAISM), uma vez que tal política é fruto das lutas e reivindicações das mulheres e movimentos feministas para que a mulher conquistasse acesso integral a serviços de saúde, considerando suas especificidades e singularidades (Martins; Malamut, 2013).

Após o levantamento das diferentes perspectivas às quais os homens são atravessados durante a pandemia, a PNAISH parece não comportar essa demanda ao priorizar majoritariamente suas ações a partir de dados epidemiológicos de morbimortalidade masculina, sem levar em consideração que há comportamentos de risco nos homens, como as atitudes violentas, que impactam as taxas de morbimortalidade também das mulheres (Schraiber; Figueiredo, 2011).

É possível refletir que, a partir desses padrões estereotipados sobre masculinidade hegemônica, que instituem a ideia de um homem autossuficiente, origina-se uma tensão entre a saúde do homem e as políticas específicas (PNAISH), pois o homem que não zela pela sua saúde por meio de atitudes de promoção e prevenção - disponibilizadas pelos serviços da Atenção Primária à Saúde (APS) - passa a sobrecarregar os serviços de emergência, onerando a saúde pública. Couto et al. (2010) salientam que, nas representações dos profissionais de saúde da APS, os homens não são caracterizados como potenciais sujeitos de cuidado e os serviços desse nível do sistema de saúde são substancialmente voltados a mulheres e crianças.

Finalmente, reitera-se que o uso do conceito de masculinidade hegemônica não é reificador nem essencialista. Ressalta-se ainda a ideia de masculinidades múltiplas, o conceito de hegemonia e a ênfase na transformação e na dinâmica, enfatizando a interseccionalidade entre os níveis local, regional e global, reconhecendo as contradições internas e as possibilidades de movimento em direção à democracia de gênero (Connell; Messerschmidt, 2013).

Apesar disso, é importante salientar que a sociedade (re)produz, historicamente, relações de gênero e que a masculinidade hegemônica é definida como uma configuração de práticas projetadas sobre as estruturas das relações de gênero (Connell;
Messerschmidt, 2013), o que, em determinadas situações, pode permitir a manutenção da dominação dos homens sobre as mulheres. Porém, é de se notar que o conceito de dominação não possui o mesmo significado de poder. De acordo com Arendt (2009), poder refere-se ao agir em comum acordo. Nesse caso, as práticas de dominação dos homens sobre as mulheres é uma resposta à perda do poder da masculinidade em relação à feminilidade.

Esclarecidos os principais aspectos conceituais e a pertinência da abordagem, a seguir analisaremos a relação homem-violência-poder através da lente teórica de Hannah Arendt.

\section{Homem-violência-poder em Hannah Arendt}

A Organização Mundial da Saúde (OMS) define a violência como o uso de força física ou poder, em ameaça ou na prática, contra si próprio, outra pessoa ou contra um grupo ou comunidade que resulte ou possa resultar em sofrimento, morte, dano psicológico, desenvolvimento prejudicado ou privação (WHO, 1996).

A definição do conceito da OMS com base no uso de força ou poder exige questionarmos: o homem age de forma violenta porque tem mais ou menos poder? De que poder estamos falando? O que é o poder? Como e por que ele se manifesta? Em Hannah Arendt, o poder é uma ação/um agir, mas um agir em comum acordo. Para a autora, o poder jamais é do indivíduo, mas entregue ao indivíduo por um grupo que lhe permitiu atuar em seu nome. A partir do momento que este grupo se desfaz, o poder se desfaz com ele. Arendt trabalha, ainda, quatros conceitos para entender melhor o poder: vigor, força, autoridade e violência, sendo fenômenos distintos e diferentes entre si (Arendt, 2009).

Para Arendt, confundimos poder com vigor, pois quando chamamos um homem de "poderoso" usamos a palavra poder de forma alegórica. Aquilo que estamos narrando é o vigor, que se trata de uma qualidade própria de um objeto ou pessoa e que se revela em relação a outras coisas ou pessoas, mas que é independente deles. Já a autoridade tem como característica o reconhecimento sem resistência por aqueles que são convocados a obedecer. A força, 
usada popularmente como sinônimo de violência é, para Arendt, uma energia liberada por meio de movimentos físicos e sociais e seria mais correto chamá-la de "força da natureza" ou "forças das circunstâncias" (Arendt, 2009).

O último conceito relevante sobre a ideia de poder, e que iremos trabalhar mais profundamente, é a violência. Para Arendt, violência possui um caráter instrumental. Por isso, há sempre uma busca pela orientação e justificativa aos seus objetivos (Arendt, 2009). A violência é, tradicionalmente, o último e o mais vergonhoso recurso utilizado nas relações entre nações e/ou na vida doméstica, sendo considerada um marco da tirania (Arendt, 2016).

A violência pode servir para representar insatisfações, trazendo a atenção do público. Algumas práticas violentas precisam do agir em conjunto, ou seja, de um acordo, já que o homem isolado sem outros que o auxiliem não teria o poder necessário para fazer o uso da violência de maneira eficaz. Apesar de ser comum encontrar violência e poder juntos, não se pode concluir que autoridade, poder e violência sejam a mesma coisa. Isso só é possível se admitirmos que poder é sinônimo de mando e obediência (Arendt, 2009).

Para Arendt a violência é um fruto das relações humanas desiguais com fins de dominação e o seu surgimento acontece quando o poder se desfaz. Neste ponto, é válido considerarmos que, na nossa cultura, a dominação é um identificador da condição masculina e um requisito para a sua socialização, relacionando o homem à violência (Alves et al., 2012).

A masculinidade baseada na dominação, seja na relação entre homens e mulheres (desigualdade de gênero) ou entre homens e homens (desigualdade multifatorial), afeta sobremaneira os sujeitos considerados subordinados (Connell; Messerschmidt, 2013). Esse padrão de masculinidade naturaliza a violência como algo inerente ao homem e como um instrumento de confirmação do seu status quo, o que promove ações que colocam a sua vida em risco e promove condutas autoritárias, sendo ambas geradoras de relações humanas violentas (Alves et al., 2012). Tal ideia de masculinidade serve de base para uma cultura patriarcal, gerando um ambiente ofensivo para as mulheres e práticas violentas no ambiente domiciliar (Silva et al., 2020).
Com advento dos movimentos feministas, esse modelo de masculinidade começa a ser confrontado. As mulheres passam a lutar por emancipação e equiparação de direitos, de forma a questionar as condições que regem as relações de gênero. Além da luta contra o domínio do homem sobre a mulher, os movimentos feministas possibilitaram às mulheres estarem à frente das causas femininas e de ocuparem a esfera pública, colocando em pauta suas demandas agora no espaço em que se faz política. Nesse deslocamento, as mulheres são inseridas em diversos setores da sociedade e isso reflete na organização financeira da família. Essa emancipação é considerada um fator relevante sobre o questionamento do patriarcado e da dominação masculina (Blay, 2014), gerando mudança nos papéis tradicionais de gênero, provocando um impacto no papel de provedor do homem (Schraiber; Figueiredo, 2011).

Ainda sobre as relações entre masculinidades e feminilidades, ressalta-se que o campo dos estudos feministas é um campo heterogêneo, permeado de diversidade de abordagens, categorias e análises (Oliveira, 2020a). Nesse contexto, destaca-se a importância dos movimentos feministas que, além da luta contra o domínio do homem sobre a mulher, vêm possibilitando às mulheres abordar a multiplicidade de posições, dessencializando as identidades - sem deixar de explicar as estruturas modeladas nessas identidades - que devem ser reconhecidas nos corpos que são atravessados por culturas e opressões diferentes e situadas em um mundo desigual, gerando transformações das masculinidades existentes. Reconhecidos em sua pluralidade, os feminismos buscam estratégias de ação política em diferentes espaços e contextos sociais, não podendo ser tratados como algo homogêneo (Larrondo; Lara, 2019; Akotirene, 2019).

Em virtude disso, rearranjam-se as relações de gênero e a perspectiva da perda de domínio masculino, ferindo a figura do macho provedor, dado por um determinado modelo hegemônico de masculinidade. Por sua vez, a insegurança em relação à saúde causada pela pandemia contesta o estereótipo da invulnerabilidade masculina. Isso pode ser percebido pela manifestação de práticas tóxicas, como violência doméstica, ou pela baixa adesão ao isolamento social 
por parte dos homens, atitudes reforçadas por várias questões socioeconômicas e por práticas de algumas masculinidades hegemônicas que alimentam esses comportamentos de risco (Mapa, 2020).

Com estas e tantas outras mudanças sociais sobre papéis de gênero, o poder do homem é questionado. É importante ressaltar que o conceito de poder em Hannah Arendt, aqui utilizado, é entendido como dominação, e o homem, na procura de garantir a sua posição de dominador e de definir sua propriedade e de exteriorizar suas angústias, utiliza a violência como um meio de tentar resolver os conflitos (Alves et al., 2012). Arendt (2009), conclui que a incapacidade de agir em conjunto e a monopolização do poder é um convite à violência, pois aqueles que perdem a capacidade de falar pelo outro dificilmente resistem à tentação de trocar o poder que está enfraquecendo pela violência.

Nesse sentido, podemos destacar, como prováveis causas do aumento da violência contra a mulher na pandemia, a perda de contato socioafetivo da mulher, a condição financeira abalada, o uso do isolamento como modo de controle da parceira, o aumento do uso de álcool e a diminuição do acesso das mulheres a fontes de ajuda (Melo et al., 2020).

Dentre essas causas, chamamos a atenção para a alteração da condição econômica da população no isolamento. Ao lançar um olhar interseccional que parte das categorias classe, raça/etnia, reconhece-se que os efeitos mais perversos da pandemia atingem as faixas mais vulneráveis da sociedade, ou seja, jovens, negros, mulheres, pobres e aqueles com menor nível de instrução. A crise sanitária só alargou as diferenças num país já extremamente desigual. Sem previsão para o final da pandemia e com a extinção precoce do auxílio emergencial em agosto de 2020, aliada ao número de trabalhadores informais, a tendência é o agravamento das condições de vida de milhares brasileiros(as) no país.

Nessa conjuntura, faz-se necessário destacar que, em meio a sistemas de opressão imbricados e presentes na sociedade, algumas masculinidades são subalternizadas em relação a outras, que se beneficiam de posições de privilégio (Hirata, 2014). A interseccionalidade apresenta-se, então, como um mecanismo de análise que nos auxilia a compreender como distintos marcadores sociais têm impacto na forma como se ascende aos direitos e às oportunidades
(Akotirene, 2019). Nessas zonas de intersecção observam-se as diferentes experiências de opressão e de privilégio das masculinidades e feminilidades. Entretanto, não devemos olhar a intersecção (gênero, classe e raça/etnia) como uma trivial soma, devemos enxergá-la como articulação que acarreta experiências substantivamente diferentes (Cesaro; Santos; Silva, 2018). Dessa forma, uma mulher, articulada por determinadas intersecções, pode se encontrar em uma posição de dominação em relação ao homem subalternizado por sua classe, raça/etnia, ressaltando que o fenômeno das experiências das masculinidades não ocorre isoladamente das feminilidades e de outras categorias interseccionais.

Nesse contexto, faz-se necessário questionar que parte da população se encontra mais vulnerável? Segundo a Pesquisa Nacional por Amostra de Domicílios (PNAD), conhecida como PNAD covid-19, do Instituto Brasileiro de Geografia e Estatística (IBGE, 2020), de maio à junho de 2020, a população negra (pretos e pardos) responde por dois terços $(66,3 \%)$ do aumento registrado pelo desemprego, agravando uma taxa que já era superior à média nos meses anteriores. Além disso, a pesquisa revelou que o número de desempregados cresceu entre os jovens negros, avançando de $18,4 \%$ para $21,0 \%$.

Ainda, historicamente, as mulheres negras sofrem com trabalhos informais, menores salários, subempregos, além da jornada dupla ou tripla, e suas reivindicações estavam voltadas para direitos e garantias trabalhistas, buscando o apoio dos seus companheiros para vencer o estigma deixado pela escravidão, o que difere o feminismo negro do feminismo de mulheres brancas. Estudos populacionais realizados no Brasil entre 2009 e 2015 registram mais de 71 milhões de famílias com $42 \%$ de mulheres responsáveis pela casa, a maior parte delas solteiras e com renda familiar per capita inferior à de famílias chefiadas por homens. Quando se comparou o percentual de mulheres que se encontram na chefia familiar com as variáveis de renda e raça, as diferenças foram significativas entre as mulheres negras e brancas. Em 2015, em domicílios chefiados por mulheres brancas, a renda domiciliar per capita é $47,3 \%$ maior do que naqueles chefiados por mulheres negras - e 40\% maior do que nos domicílios chefiados por homens negros (Ipea, 2015). 
Apesar de o maior impacto da taxa de desemprego incidir sobre as mulheres, sobretudo as negras, que subiu de 12,2\% para 14,1\%, em comparação com 11,1\% dos homens (IBGE, 2020), destacam-se os diferentes efeitos do desemprego entre homens e mulheres. À medida que a pandemia avança e impacta de forma substancial a ocupação das mulheres, intensifica-se o cuidado não remunerado e a dedicação das mulheres com as tarefas domésticas, historicamente destinada a elas. Por outro lado, os homens comportam-se de outras formas, impactados pelos modelos de masculinidade hegemônica. Portanto, o gênero também é um marcador de desigualdades, que deve ser considerado na forma como homens e mulheres se comportam diante dos graves efeitos da pandemia.

É possível pensar que, a partir dessa alteração do cenário social e econômico que atinge de forma desigual as populações mais vulneráveis, o provimento financeiro associado ao isolamento significa a retirada abrupta do homem da esfera pública, provocando o deslocamento das suas atividades (Figura 2). Conforme Silva (2017), para Arendt, existem três atividades que se fazem presentes na experiência do homem em sua condição social: o trabalho, que consiste na manutenção da vida; a obra, ou a atividade de produção ou fabricação; e a atividade de ação, que inclui a atividade política e a vida pública. É nessa esfera que o sujeito desenvolve a defesa dos interesses que são comuns a todos e geralmente ocupada pelo homem.

O homem como chefe da família, até então, não era limitado por qualquer lei ou justiça. Garantindo a manutenção da ordem doméstica, exercia um poder totalitário sobre vida e morte de todos que estavam presos na esfera privada. Essa esfera era considerada espaço das necessidades e do ocultamento, que se resumia em proteção e manutenção da vida. Era considerado o espaço da família, mas lembrando que nessa esfera se originam todos os tipos de repressão, sendo a dominação e a violência marcas da esfera privada, e não da pública, salvo em casos de guerra. Dessa forma, a violência contra a mulher não é algo novo em nossa sociedade, é fruto de uma cultura patriarcal, que contribuiu para que essa prática fosse naturalizada (Saffioti, 2004).

Além da esfera privada, o homem encontrase despossado da sua capacidade social mais importante - a ação política. A retirada do homem da esfera pública o desloca de seu papel socialmente aceito, de bom profissional, de membro da família responsável por sair de casa para garantir o sustento e de sujeito que praticamente não faz nada dentro do ambiente doméstico. Dessa forma, é nítido que a construção social com base na cultura patriarcal é um incentivo ao controle de gênero pela violência, limitando a liberdade, a sexualidade e as atuações, resultando dessa dominação patriarcal a violência contra a mulher (Oliveira, 2020b).

O modelo de masculinidade hegemônica, entendida como normativa, está cotidianamente tornando o homem suscetível a conflitos internos e externos, diante da necessidade de se adaptar à nova realidade, ao mesmo tempo em que luta pela manutenção da hegemonia e da dominação sobre as feminilidades e outras masculinidades marginalizadas, chegando a fazer uso de práticas tóxicas, como a violência em todas as suas manifestações (Connell; Messerschmidt, 2013). É importante ressaltar que as masculinidades marginalizadas coexistem com as hegemônicas e que o homem caminha entre essas posições conforme ele enfrenta diferentes situações sociais.

É significativo ressaltar que esse homem, agente causador da violência, não é um monstro, mas uma pessoa igualmente normal às outras. Para Arendt (2003), um ser humano normal é um sujeito comum que faz o que é esperado em relação às demandas sociais, que são (re)produzidas pelas classes dominantes, na intenção de manter o modelo estabelecido. É importante reforçar que nem todos os homens lutam pela dominação, ou que são maus, ou que não devemos acreditar em dias melhores. Segundo a autora, a incapacidade de pensar, ou seja, a incapacidade de distanciar-se do mundo para examiná-lo, gera ingenuidade face às estratégias do poder e incapacidade de pensar sobre os movimentos micro e macropolíticos relacionados aos poderes instituídos, que esvaziam a coisa pública e impedem a percepção sobre o desmantelamento do poder político pela violência institucionalizada. Pensamento não é algo abstrato, mas a ação de afirmar o que se deseja como valor ou recusar o que se indica como aniquilamento. 


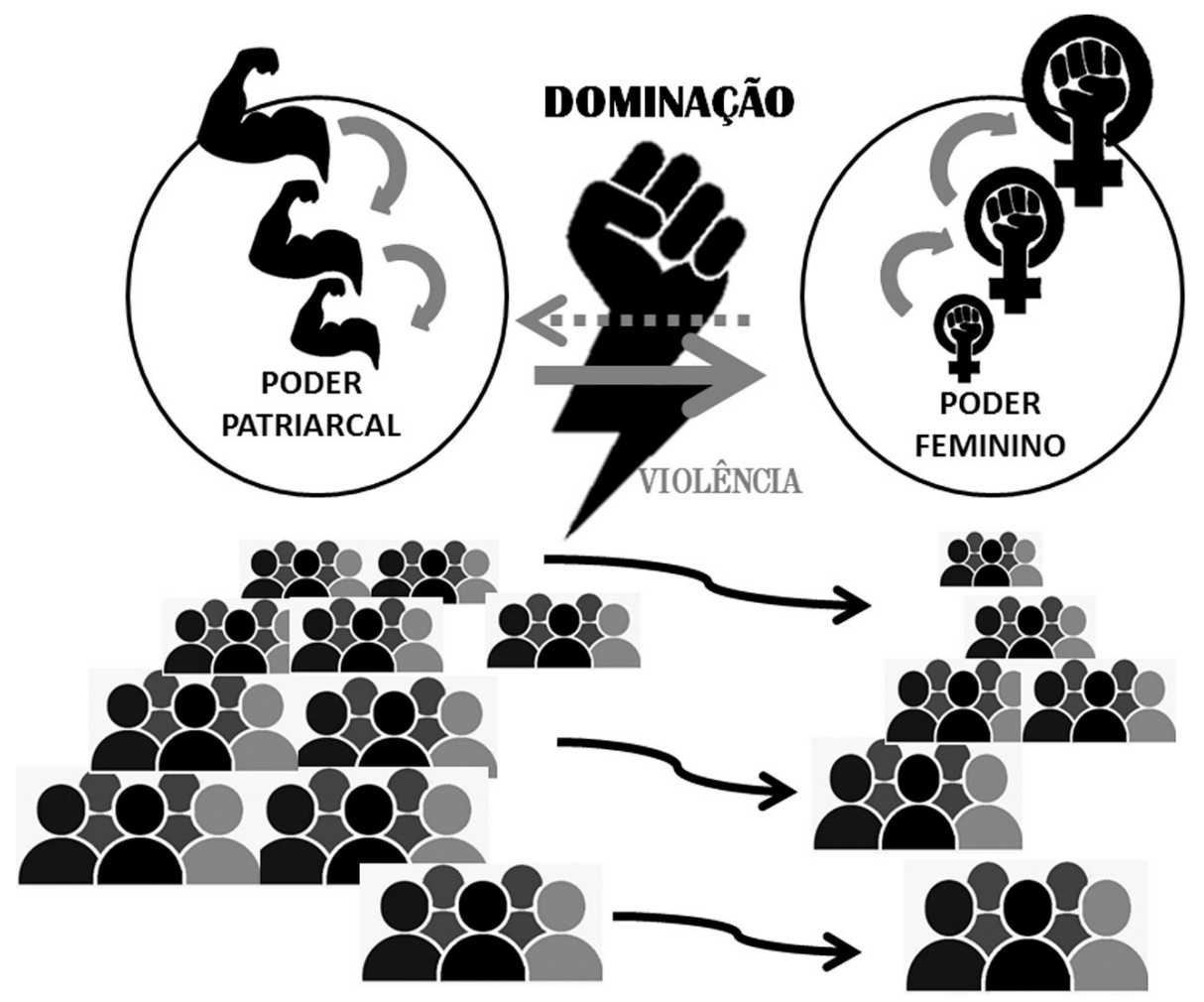

Para contribuir com essa mudança de olhar, propomos o questionamento da masculinidade hegemônica por meio do exercício do pensamento segundo Hannah Arendt. A partir da análise do estatuto do pensar, Arendt apresenta na obra A Vida do Espírito uma proposta pedagógica que educa para o pensamento, que ela traduz como uma capacidade de estar atento às coisas e aos acontecimentos. A autora diferencia conhecimento de pensamento, de forma que, o primeiro está focado na busca da verdade e quando a encontra limita-se a ela, encerrando a busca. Já o pensamento seria o exercício de ir além da verdade, buscando o significado das coisas no mundo, sempre novo e imprevisível. Dessa forma, quando nos referimos ao questionamento da masculinidade hegemônica, estamos defendendo o pensamento que busca novos sentidos nas relações entre as diferentes interseções. Para isso, propomos que as instituições adotem a proposta pedagógica de Arendt e rompam com o caráter iluminista de educação que permanece educando para o conhecimento. Para que isso se efetive na construção de uma cultura de paz, solidária, tolerante e democrática, é preciso buscar os significados do mundo, não apenas as suas verdades (Arendt, 1995).

Ao questionarmos a masculinidade hegemônica por meio do aumento da expressão de diversas formas de masculinidade possibilitamos uma maneira de constituir o "ser homem" de forma mais humana e menos opressiva. Com isto, a masculinidade vista como hegemônica sofre contestação, seja pela resistência das mulheres e/ou dos próprios homens como portadores de masculinidades alternativas, o que facilita a transformação das relações de gênero e da dominação masculina (Connell; Messerschmidt, 2013).

Essas masculinidades alternativas geram nos homens autores de violência de gênero uma crise, vislumbrando a perda do seu lugar em mundo social. É uma crise de certezas, modelos, padrões e estereótipos que implica na mudança do paradigma de ser homem, sendo considerada uma crise recente que implica transformação, mudanças, abertura, escuta e acolhimento e não apenas julgamento e 
punição. A covid-19 pode ser um potencializador para esse colapso, como já mencionado.

Além de ser encarada como algo negativo, vale aqui ressaltar a definição de crise para Arendt como uma situação inquietante que permite uma reflexão e que favorece a oportunidade do pensamento e da análise crítica, assim "uma crise nos obriga a voltar às questões mesmas e exige respostas novas ou velhas, mas, de qualquer modo, julgamentos diretos" (Arendt, 2016, p. 223).

Arendt nos direciona a pensar violência e poder além do senso comum, dos conhecimentos mais vigentes e dos preconceitos (juízos pré-formados), já que esses dois conceitos são tratados por estudiosos das mais diversas áreas e em outras correntes filosóficas, geralmente em conjunção. Compreende-se, dessa forma, que alguns homens acabam por utilizar a violência que, segundo Arendt (2009), é uma ação que pode indicar insatisfação, além de ser fruto das relações humanas desiguais, com o objetivo de manter dominação.

É importante ressaltar que, quando se faz presente a violência, o poder se desfaz. Diante dessa diminuição do poder da relação entre homem e mulher e do aumento da violência, em Arendt identificamos a seguinte elucidação: a nossa capacidade de natalidade, ou seja, de nos renovarmos enquanto sujeitos e/ou como sociedade, em qualquer momento da existência. Há em nós a capacidade de natalidade que consiste em colocarmos no mundo constantemente novos recém-chegados cujo agir não pode ser previsto por aqueles que já estão no mundo. Para não se trata de um conceito puramente biológico, mas sim da nossa capacidade de fazer o novo começo em vários momentos da existência, seja particular ou coletivamente, sendo a natalidade também a iniciação para a existência política. Assim, diante das relações humanas, há sempre a possibilidade do novo, do recomeço (natalidade) (Arendt, 2009).

\section{Conclusões finais}

Considerando-se o trajeto trilhado neste ensaio sobre as masculinidades, vale ainda ressaltar que as práticas corporais também estão ligadas aos modelos de masculinidades e feminilidades hegemônicos, que se materializam por meio da representação e uso dos corpos. Nesse aspecto, os corpos participam na ação social ao produzir condutas sociais, entrelaçandose aos contextos sociais, como, por exemplo, o contexto da pandemia. Essas masculinidades e feminilidades hegemônicas incorporadas são tanto objetos como agentes da prática social, em que as relações de gênero são sempre consideradas arenas de tensão. Falar de uma configuração de prática significa falar daquilo que as pessoas realmente fazem, não naquilo que é esperado ou imaginado, como, por exemplo: a divisão sexual do trabalho no cuidado das crianças, no mercado de trabalho, no provimento financeiro, nas tarefas domésticas, nas relações entre pais e filhos(as), entre outras. Essas masculinidades e feminilidades, que são vivenciadas pelo corpo, envolvem relações de tensão, uma vez que estão constantemente se definindo numa relação dinâmica em rede.

Historicamente, os esforços do movimento de mulheres em direção aos projetos de mudanças vêm causando tensões nas relações de gênero, nos âmbitos locais, regionais e globais, questionando continuamente um determinado padrão de masculinidade hegemônica, gerando uma tensão entre a busca pela estabilização e restituição do poder patriarcal e o estabelecimento de novas formas de relações de gênero e redefinição do modelo de masculinidade hegemônica.

A pandemia aumenta a arena de tensão nas relações de gênero, uma vez que as masculinidades incorporadas se encontram limitadas ao espaço privado, perdendo sua expressão no espaço público, relacionado ao estabelecimento da sua reputação. Assim, diante das reformas históricas de gênero acrescidas da instabilidade provocada pela pandemia da covid-19, observa-se o aumento da violência domiciliar como efeito da diminuição do poder do homem. $O$ poder que consiste em falar por e do agir em comum acordo. Atribuído ainda ao deslocamento desse homem da esfera pública e o questionamento da sua dominação na esfera privada, as práticas tóxicas e violentas aparecem na tentativa de estabilizar o modelo de masculinidade definido pelo poder patriarcal, ou de tentar reconstituí-lo em novas configurações.

Nesse sentido, como podemos (re)pensar a participação social dos corpos nos contextos sociais que possam dar passagem a novas possibilidades 
se ser/viver/agir de homens e mulheres? De que forma podemos buscar fornecer uma solução a essas tensões? Seriam os homens verdadeiramente maus ou apenas ingênuos? O exercício do pensamento, como a busca pelo sentido, poderia contribuir para banir a forma ingênua como nos colocamos diante das coisas do mundo? A PNAISH não deveria focar na promoção de saúde, por meio de ações de educação que busquem romper com modelos positivistas ainda focados apenas no conhecimento?

Essas e outras questões foram e são para nós uma forma de ação, uma vez que pensar não se trata de abstrair, mas de construir novos sentidos e movimentos de mudança, ressignificando as masculinidades, sendo a pandemia uma oportunidade para construir novas possibilidades de ser, viver e agir nas relações estabelecidas nesse cenário de desigualdade e injustiça social.

\section{Referências}

ACABAR com a violência contra as mulheres no contexto do COVID-19. ONU Mulheres, 30 mar. 2020. Disponível em: <https://bit.ly/32lx3VN>. Acesso em: 13 abr. 2020.

AKOTIRENE, C. Interseccionalidade. São Paulo: Sueli Carneiro; Pólen, 2019.

ALVES, R. A. et al. Men, victims and perpetrators of violence: the corrosion of public space and the loss of the human condition. Interface, Botucatu, v. 16, n. 43, p. 871-883, 2012. DOI: 10.1590/S141432832012005000049

ARENDT, H. A vida do espírito. 38. ed. Rio de Janeiro: Relume Dumará, 1995.

ARENDT, H. Eichmann em Jerusalém: uma reportagem sobre a banalidade do mal. Tradução: Ana Corrêa Silva. Coimbra: Tenacitas, 2003.

ARENDT, H. A condição humana. Tradução: Roberto Raposo. 1o. ed. Rio de Janeiro: Forense Universitária, 2008.

ARENDT, H. Sobre a violência. Tradução: André de Macedo Duarte. Rio de Janeiro: Civilização Brasileira, 2009.

ARENDT, H. Entre o passado e o futuro. São Paulo: Perspectiva, 2016.
BATISTA, K. S. A.; LIMA, A. F.. Por uma implicação política e conceitual nos estudos sobre homens, masculinidades e violência de gênero. Semina: Ciências Sociais e Humanas, Londrina, v. 38, n. 2, p. 175-188, 2017.

DOI: $10.5433 / 1679-0383.2017 v 38 n 2 p 175$

BLAY, E. Al. Violência contra a mulher: um grave problema não solucionado. In: BLAY, E. A. (Org.). Feminismos e masculinidades: novos caminhos para enfrentar a violência contra a mulher. São Paulo: Cultura Acadêmica, 2014. p. 13-28.

BRASIL. Boletim Epidemiológico o8. Brasília, DF: Ministério da Saúde, 2020.

CESARO, B. C.; SANTOS, H. B.; SILVA, F. N. M. Masculinidades inerentes à política brasileira de saúde do homem. Revista Panamericana de Salud Publica, Washington, DC, v. 42, e119, 2018. DOI: 10.26633/RPSP.2018.119

CONNELL, R.; MESSERSCHMIDT, J. Masculinidade hegemônica: repensando o conceito. Revista Estudos Feministas, Florianópolis, v. 21, n. 1, p. 241-282, 2013.

COUTO, M. T. et al. O homem na atenção primária à saúde: discutindo (in)visibilidade a partir da perspectiva de gênero. Interface, Botucatu, v. 4, n. 33, p. 255-270, 2010. DOI: 10.1590/S141432832010000200003

HIRATA, H. Gênero, classe e raça: interseccionalidade e consubstancialidade das relações sociais. Tempo Social, São Paulo, v. 26, n. 1, p. 61-73, 2014. DOI: 10.1590/So10320702014000100005

IBGE - INSTITUTO BRASILEIRO DE GEOGRAFIA E ESTATÍSTICA. Pesquisa Nacional por Amostra de Domicílios Covid-19. Rio de Janeiro: IBGE, 2020. Disponível em: <https://bit.ly/3agHwGD>. Acesso em: 8 nov. 2020.

IPEA - INSTITUTO DE PESQUISA ECONÔMICA APLICADA. Retrato das desigualdades de gênero e raça. Brasília, DF: Ipea, 2015. Disponível em: <https://bit.ly/32pZrga>. Acesso em: 8 nov. 2020.

LARRONDO, M.; LARA, C. P. Activismos feministas jóvenes en América Latina: dimensiones y perspectivas conceptuales. In: LARRONDO, M.; 
LARA, C. P. (Ed.). Activismos feministas jóvenes: emergencias, actrices y luchas en América Latina. Buenos Aires: CLACSO, 2019. p. 21-38.

MAPA brasileiro da Covid-19. InLoco, 2020. Disponível em: <https://bit.ly/zuVpOAf >. Acesso: 24 maio 2020.

MARTINS, A. M.; MALAMUT, B. S. Análise do discurso da Política Nacional de Atenção Integral à Saúde do Homem. Saúde e Sociedade, São Paulo, v. 22, n. 2, p. 429-440, 2013. DOI: 10.159o/

So104-12902013000200014

MELO, B. D. et al. Violência doméstica e familiar na COVID-19. Rio de Janeiro: Fiocruz. 2020.

MLAMBO-NGCUKA, P. Violência contra mulheres e meninas é pandemia das sombras. 2020. $O N U$ Mulheres, 7 abr. 2020. Disponível em: <https://bit.ly/ 3e4DGBo>. Acesso em: 13 abr. 2020.

OLIVEIRA, A. C. A. Lélia Gonzalez e o pensamento interseccional: uma reflexão sobre o mito da democracia racial no Brasil. Revista Interritórios, Recife, v. 6, n. 10, 2020a. DOI: 10.33052/inter.v6i10.244895

OLIVEIRA, R. L. S. Violência institucional e combate aos direitos reprodutivos femininos.
Revista Espaço Acadêmico, Maringá, v. 19, n. 221, p. 37-49, 2020b.

PAHO - PAN AMERICAN HEALTH

ORGANIZATION. Masculinities and health in the region of the Americas: executive summary. Washington, DC: 2019.

SAFFIOTI, H. Gênero, patriarcado, violência.

São Paulo: Editora Fundação Perseu Abramo, 2004.

SCHRAIBER, L. B.; FIGUEIREDO, W. S.

Integralidade em saúde e os homens na perspectiva relacional de gênero. In: GOMES, R. (Org.). Saúde do homem em debate. Rio de Janeiro: Fiocruz, 2011. p. 19-38.

SILVA, M. L. A ideia de espaço público em Hannah Arendt. Cadernos Zygmunt Bauman, São Luís, v. 7, n. 13, p. 1317-133, 2017.

SILVA, E. O. et al. O patriarcado como um fator de risco criminal: uma breve análise do comportamento do agressor no feminicídio. Revista Brasileira de Direito e Gestão Pública, Pombal, v. 8, n. 2, p. 193-203, 2020.

WHO - WORLD HEALTH ORGANIZATION. Violence: a public health priority. Geneva: 1996.

\section{Contribuição dos autores:}

Santos e Andrade foram responsáveis pela concepção e desenvolvimento do estudo, análise de dados e redação do artigo. Cordeiro e Sipioni redação do artigo. Barbosa, Demarchi e Lima análise e interpretação dos dados. Todos os autores participaram da revisão crítica do manuscrito e aprovaram a versão final.

Recebido: 30/07/2020

Reapresentado: 23/12/2020

Aprovado: 01/02/202I 